\title{
Efecto de dos preparados probiótico sobre los parámetros productivos y reducción de diarreas en cerdos pre y post destete
}

Effect of two probiotic preparations on the production parameters and reduction of diarrhea in pre and post waning pigs

José E. Miranda, ${ }^{1}$ Alfredo Marín ${ }^{1}$, Darío Baño ${ }^{2}$ y Luis Hidalgo ${ }^{2}$

\section{RESUMEN}

Evalúa la contribución alimenticia de dos biopreparados probióticos sobre los parámetros productivos y reducción de diarreas en cerdos pre y post destete. Se realizaron 2 experimentos, se utilizaron 14 cerdos híbridos CC21 (Yorkshire - Landrace/ L35 Duroc) en primero y 42 en segundo respectivamente. Se confeccionaron grupos (control y dos en estudio), peso y edad homogéneos, todos en iguales condiciones de manejo y alimentación, Bioprepado A: contenía leche ácida y Biopreparado B: cultivo mixto de baterías y levaduras. La dosis aplicada fue 3 y $5 \mathrm{~mL}$ por animal en días alternos, vía oral, durante 33 y 35 días respectivamente. En los dos experimentos realizados, los animales con mejores resultados fueron los aplicados biopreparado B, en los parámetros ganancia de peso $7.8 \mathrm{~kg}$, ganancia media diaria $223 \mathrm{~g}$ en el primer experimento y $5.8 \mathrm{~kg}, 113 \mathrm{~g}$ y $6.5 \%$ de eficiencia alimenticia respectivamente en el segundo, todos sobre grupo control. Los animales tratados con biopreparados se logró reducir los trastornos diarreicos hasta 8 y $3 \%$ respectivamente. El uso de biopreparados probióticos es económico y rentable para las categorías estudiadas; además se logra mejorar los indicadores bioproductivos y la salud del animal.

Palabras clave: cultivo mixto; ganancia de peso; lechones; probiótico.

\section{ABSTRACT}

Evaluate the nutritional contribution of two probiotic biopreparates on the productive parameters and reduction of diarrhea in pre and post weaning

1 Universidad Central Marta Abreu de Las Villas. Santa Clara, Cuba.

2 Escuela Superior Politécnica de Chimborazo. Riobamba, Ecuador. 
pigs. Two experiments were performed, 14 CC21 (Yorkshire - Landrace / L35 Duroc) hybrid pigs were used in first and 42 second respectively. Groups were made (control and two under study), weight and homogeneous age, all under equal conditions of handling and feeding, Bioprepado A were prepared: containing milk bioproduct acid and B: mixed culture of batteries and yeasts, the applied dose was 3 to $5 \mathrm{~mL}$ per animal, every other day, orally for 33 and 35 days respectively. In both experiments, animals with better results were applied I bioproduct B, in weight gain $7.8 \mathrm{~kg}$ parameters, Average daily gain $223 \mathrm{~g}$ Food efficiency $12.8 \%$ in the first and $5.8 \mathrm{~kg}, 113 \mathrm{~g}$ and $6.5 \%$ respectively in the second all about control group, Biopharmaceuticals treated animals was reduced diarrheal disorders to 8 and $4 \%$ respectively. The use of probiotics Biopharmaceuticals is economical and profitable for the categories studied; also it achieved bioproductive indicators and improve animal health.

Keywords: mixed crop; piglets; probiotic; weight gain.

\section{INTRODUCCIÓN}

Una alternativa al uso de antibióticos son las bacterias lácticas probióticas suministradas a través de inóculos, con el propósito de equilibrar la microbiota intestinal (García et al., 2006). Los probióticos usados en cerdos reducen o eliminan los patógenos en el tracto gastrointestinal, así como residuos de antibióticos y otras sustancias análogas en productos finales, mejorando el índice de conversión y reduciendo la incidencia de diarreas (Parra, 2010).

La utilización de probióticos en la dieta depende en parte de la cepa utilizada; pues, no todas las cepas tienen la misma capacidad de modulación de la microflora intestinal o de unirse a las células intestinales (Cabrera y García, 2012). Los mejores probióticos son aislados de los intestinos de los cerdos, motivo por el cual este estudio pretendió buscar una alternativa para reducir o eliminar el uso de antibióticos en cerdos mediante la caracterización de bacterias lácticas aisladas del intestino grueso de porcinos adultos y verificar su desempeño in vitro para el tratamiento de infecciones bacterianas durante el destete (García et al., 2005 y Parra, 2010). Por la importancia que tiene en la explotación porcina nos proponemos el siguiente objetivo; evaluar la contribución alimenticia del BIOPRANAL como probiótico en los cerdos de ceba, teniendo en cuenta los parámetros bioproductivos y del bienestar de los mismos. 


\section{MATERIALES Y MÉTODOS}

Se realizaron 2 experimentos:

Experimento 1, se trabajaron con 14 cerdos, confeccionaron dos grupos de 9 animales en la categoría crías hasta el destete (control y estudio). Mientras tanto en el experimento 2, se utilizaron 42 cerdos, agrupados en (control, 2 estudios) con 14 animales de la categoría pre-ceba, homogéneos en edad y peso en los dos experimentos. Todos en un mismo sistema de alimentación y manejo. Los animales de la raza híbrida CC21 (Yorkshire - Landrace/ L35 Duroc). Los biopreparados probióticos utilizados fueron; Biopreparado A: leche ácida (L acidófilo) y Biopreparado B: Biopreparado A + levadura K. marcianus supp fragilis. Los medios biológicos fueron obtenidos en el Laboratorio de Fermentaciones del Centro de Investigaciones Agropecuarias (CIAP) de la Facultad de Ciencias Agropecuarias. La administración del medio biológico se realizó todos los días alternos a las 7 am, a razón de 3 y $5 \mathrm{~mL}$ por animal por tratamiento, para homogenización el biopreparado fue inoculado en $300 \mathrm{~g}$ alimento y $300 \mathrm{~mL}$ de agua, el experimento duró 47 días el primero y 56 días el segundo respectivamente. El registro de control diarreico fue diariamente a toda la masa en experimento. La cantidad de alimento consumido en el estudio fue de 42 y $112 \mathrm{~kg}$ dieta por animal. La alimentación suministrada contenía la siguiente característica bromatológica 96.27 \% MS; 16.16 \% PB; 2.4 \% FAD y 4.6 \% Cz. Para calcular la ganancia de peso, ganancia media diaria y eficiencia alimenticia se pesaron al inicio, final y 3 intermedios cada 15 días, mediante una báscula manual con una capacidad de $50 \mathrm{~kg}$. Para calcular el parámetro productivo se utilizó la siguiente fórmula: Ganancia de peso $(\mathrm{GP})=$ Peso Final - Peso Inicial; Ganancia media diaria $(\mathrm{GMD})=\mathrm{GP} / 56$ días; Eficiencia alimenticia $(\mathrm{EA})=$ GP/consumo de alimento $\times 100$; Conversión alimenticia (CA) = Consumo de Alimentos/GP; Relación de la eficiencia proteica (PER) = GP/Consumo de Proteína Bruta. Se utilizó un diseño Completamente Aleatorizado. Para los parámetros productivos y de salud se utilizó el procedimiento de ANOVA de Medidas Repetidas con el test de Tukey para las comparaciones entre grupos, utilizando el programa estadístico SAS (v. 11). 


\section{RESULTADOS}

Experimento 1, en cerdos en la categoría cría al destete.

Tabla 1. Comportamiento de ganancia de peso y incidencia de diarrea en el experimento 1.

\begin{tabular}{ccccc}
\hline Indicadores & Control & \pm ES & Biopreparado B & \pm ES \\
\hline PV-Neonato $(\mathrm{kg})$ & $5.53^{\mathrm{b}}$ & \pm 0.04 & $6.35^{\mathrm{a}}$ & \pm 0.10 \\
PV- Destete $(\mathrm{kg}$ & $11.014^{\mathrm{b}}$ & \pm 1.26 & $18.92^{\mathrm{a}}$ & \pm 1.26 \\
GMD $(\mathrm{g})$ & $234.34^{\mathrm{b}}$ & \pm 9.74 & $402.28^{\mathrm{a}}$ & \pm 9.74 \\
Incidencia de diarrea & $35 \%$ & & - & \\
\hline
\end{tabular}

${ }^{\text {a, b }}$ superíndice en la misma fila difiere $\mathrm{p}<0.05$ (Duncan, 1955)

En la tabla 1, podemos apreciar que el grupo de animales tratados con el biopraparado B, se logró ganar $18.92 \mathrm{~kg}$ sobre el grupo control representando un $71.17 \%$ donde existe diferencia significativa $(\mathrm{P}<0,05)$ sobre grupo control. Los animales del grupo que fueron suplementados obtuvieron menor cantidad con lechones con diarreas, sin embargo, los animales del grupo control presento hasta un 35\% con diarreas.

Experimento 2. Cerdos en la categoría pre-ceba.

Tabla 2. Medias obtenidas al suplementar biopreparados probióticos A y B, en cerdos.

\begin{tabular}{ccccccc}
\hline Parametros & Control & \pm ES & $\begin{array}{c}\text { Biopreparado } \\
\text { A }\end{array}$ & \pm ES & $\begin{array}{c}\text { Biopreparado } \\
\text { B }\end{array}$ & \pm ES \\
\hline GP (kg) & $6.28^{\mathrm{bc}}$ & \pm 0.82 & $7.42^{\mathrm{bc}}$ & \pm 0.82 & $12.54^{\mathrm{a}}$ & \pm 0.82 \\
GMD (g) & $112.88^{\mathrm{bc}}$ & \pm 0.014 & $148.57^{\mathrm{bc}}$ & \pm 0.014 & $223.92^{\mathrm{a}}$ & \pm 0.014 \\
EA (\%) & 5.60 & \pm 0.90 & 7.52 & \pm 0.90 & $12.43^{\mathrm{a}}$ & \pm 0.90 \\
CA & $9.47^{\mathrm{bc}}$ & \pm 1.49 & $13.4^{\mathrm{bc}}$ & \pm 1.49 & $18.28^{\mathrm{a}}$ & \pm 1.49 \\
PER & $0.342^{\mathrm{bc}}$ & \pm 045 & $0.407^{\mathrm{bc}}$ & \pm 045 & $0.615^{\mathrm{a}}$ & \pm 045 \\
Incidencia de diarrea & $20.3 \%$ & & - & & - & \\
\hline
\end{tabular}

a, b c superíndice en la misma fila difiere $\mathrm{p}<0.05$ (Duncan, 1955) 
En la tabla 2, se reflejan los resultados obtenidos en el segundo experimento, donde se observa la Ganancia de peso en cerdos de la categoría ceba que fueron suministrado el Biopreparado B, obtuvieron $12.54 \mathrm{~kg}$ sobre el grupo control representando un $90.6 \%$, mientras tanto el grupo con el Biopreparado A, alcanzó $7.42 \mathrm{~kg}$ de ganancia de peso, siendo un $18.15 \%$, donde existe una diferencia significativa con $(\mathrm{P}<0,05)$. Los parámetros evaluados resultan ser superiores el grupo tratado con Biopreparado B en cuanto a GMD alcanzando $223.92 \mathrm{~g}$, mientras el grupo suministrado con Biopreparado A $148.57 \mathrm{~g}$ por encima del control, en 90 y $31.1 \%$ respectivamente siendo una diferencia significativa de $(\mathrm{p}<0,05)$. Con el suministro de Biopreparado probiótico se logró reducir la presencia de diarreas hasta un $80 \%$ de cada grupo. Cuando estos datos se extrapolan a la población nos percatamos que con el empleo del probiótico se previene la diarrea en el $20 \%$ de los cerdos, es decir, el empleo de probiótico y el síndrome diarreico agudo son independientes $(\mathrm{p}<0,05)$.

Valoración económica al utilizar Biopreparados probióticos como suplemento dietético en cerdos en las categorías preceba y ceba.

Al realizar el análisis costo-beneficio de estos experimentos se obtiene, en el primer ensayo los tratados con el medio biológico Biopreparado A presentaron una ganancia de $\$ 132,31$ pesos por encima de grupo control, mientras en el segundo experimento los animales de control y los tratados con Biopreparado A tuvieron una pérdida de $\$ 26.00$ y 11.00 pesos respectivamente, no siendo así los tratados con Biopreparado B, ganaron $\$$ 29.72 pesos.

\section{DISCUSIÓN}

\section{Experimento 1}

Nuestros resultados coinciden con lo planteado por varios autores, relacionado con la estimulación de los microorganismos en la síntesis de enzimas, vitaminas, nutrientes y otros elementos esenciales que favorecen el desarrollo bioproductivo delos cerdos enla categoría preceba, proporcionando ventajas en el orden de la salud y la economía en la producción (Cabrera y García, 2012). Rosmini (2004), plantea que la administración de cultivos de levaduras o bacterias lácticas como probiótico en cerdos, promueve el crecimiento, reduce las muertes y debilidades causadas por situaciones estresantes. Este hallazgo coincide con Parra (2010), y Cabrera (2012) 
quienes señalaron que los beneficios de las bacterias probióticas, incluyen la protección de la digestión de la lactosa, la modulación del sistema inmune.

\section{Experimento 2}

Nuestros resultados concuerdan con los obtenidos por Michelan (2012) y Marin (2008) quienes en investigación realizada evaluaron el efecto probiótico de bacterias ácido-lácticas en un sustrato de miel proteica suministrado a cerdos demuestra un ligero aumento en ganancia de peso. Aun cuando no existen evidencias demostradas sobre el efecto de los probióticos en la digestibilidad de los nutrientes, como se ha informado, Ramírez et al. (2011), es lógico pensar en algún efecto de esta utilización. Se ha informado que los promotores o estimuladores de crecimiento mejoran el crecimiento de los cerdos, la conversión alimentaria y los rendimientos reproductivos (Chiquieri et al., 2006 y García et al., 2006). El efecto protector de los probióticos ante el síndrome diarreico agudo en cerdos puede deberse a que los probióticos tienen una actividad inhibidora sobre toxinas producidas por entero patógenos, a la producción de bacteriocinas, ácidos orgánicos, sustancias éstas con actividad antibiótica y H2O2, que suprimen el crecimiento de patógenos y no patógenos, además refuerzan la inmunidad mucosal a través del aumento de los niveles secretorios de $\operatorname{IgA}$ y el número total de linfocitos e incrementan los niveles de ácido láctico en el ciego con disminución del $\mathrm{pH}$ en este sitio, lo cual crea un ambiente intestinal que contribuye a la reducción de los niveles de microorganismos potencialmente patógenos como coliformes y otras enterobacterias, mientras tanto se va incrementando los Lactobacillus acidophilus (Isay, 2006).

Valoración económica: El uso de los probióticos en la producción animal ha tomado un auge en estos tiempos, por la importancia de los mismos en las producciones orgánicas y de sostenibilidad que se requieren hoy, ya que se elimina el uso de antibióticos y es de fácil producción en las pequeñas unidades con un mínimo de recursos (Marín, 2008).

\section{CONCLUSIONES}

Con la adición del Biopreparado B se logra que los cerdos en las categorías preceba-ceba incrementa significativamente los indicadores productivos como: peso final, ganancia de peso, ganancia media diaria, conversión alimenticia y eficiencia alimentaria. Además se logra la no presencia de diarreas, ni trastornos digestivos, ni muertes por estas causas. Así como un incremento de los ingresos en los grupos tratados. 


\section{REFERENCIAS BIBLIOGRÁFICAS}

Cabrera, Yaneris y García, Anahí. 2012 «Rasgos de comportamiento de cerdas en una granja cubana de producción porcina». Revista Computadorizada de Producción Porcina. Vol. 19, $\mathrm{N}^{\circ}$ 1. La Habana: Instituto de Investigaciones Porcinas. 59-63.

Chiquieri, Jhon y otros. 2006. «Probiótico y prebiótico en la alimentación de cerdos en crecimiento y terminación». Revista Archivos de Zootecnia. Vol. 55, num. 211. Córdoba: Universidad de Córdova. 305-308

Duncan DB. 1955 «Multiple range and multiple F test». International Biometric Society. Vol. 11, N 1. 1-42.

Garcia, Juima y otros. 2006. «Nota acerca del efecto de un probiótico en la digestibilidad de nutrientes en cerdos jóvenes». Revista Computadorizada de Producción Porcina. Vol. 13, N 1. La Habana: Instituto de Investigaciones Porcinas. 36-38

García, Yanelys y otros. 2005. «Probióticos: una alternativa para mejorar el comportamiento animal». Revista Cubana de Ciencia Agrícola. Vol. 39, $\mathrm{N}^{\circ}$ 2. La Habana: Instituto Ciencia Animal. 129-140.

Isay, Susana. 2006. «Probióticos e prebióticos: o estado da arte». Revista Brasileira de Ciências Farmacêuticas. Vol.42, N 1 . São Paulo: Universidade de São Paulo. 1-16.

Marín, Alfredo. 2008. Desarrollo de la tecnología de producción del BIOPRANAL. Tesis en opción al grado científico de doctor en ciencias. Universidad Central de Las Villas, Cuba.

Michelan, Andre. 2002. «Utilização de probiótico, ácido orgânico e antibiótico em dietas para coelhos em crescimento: Ensaio de digestibilidade, avaliação da morfometria intestinal e desempenho». Revista Brasileira de Zootecnia. Vol. 31, Nº 6 Viçosa: Universidade Federal de Viçosa. $2227-$ 2237

Parra, Adolfo 2010. «Bacterias lácticas: papel funcional de los alimentos». Revista Facultad de ciencias Agropeciarias. Vol. 8, N 1. Cauca: Universidad de Cauca. 93-105.

Ramírez, José y otros 2011. «Bacterias lácticas: importancia en alimentos y sus efectos en la salud». Revista fuente. Vol. 2, N 7 . Sevilla: Universidad de Sevilla. 1-8. 
Rosmini, Meryy otros. 2004. «Producción de pro bióticos para animales de abasto: importancia del uso de la micro biota intestinal indígena». Revista Mexicana De Ingeniería Quimica Vol. 3, N 1. México: Universidad Autónoma del Estado de México. 181-191

Presentado: 08/02/2017

Aceptado: 09/05/2017

\section{Correspondencia}

José Miranda Yuquilema efra_miranda@outlook.com 